\title{
Discours
}

Revue de linguistique, psycholinguistique et

informatique. A journal of linguistics, psycholinguistics and computational linguistics

27 | 2020

Varia

\section{Where lol Is: Function and Position of lol Used as a Discourse Marker in YouTube Comments}

\section{Célia Schneebeli}

\section{OpenEdition}

\section{Journals}

\section{Electronic version}

URL: http://journals.openedition.org/discours/10900

DOI: $10.4000 /$ discours. 10900

ISSN: 1963-1723

Publisher.

Laboratoire LATTICE, Presses universitaires de Caen

\section{Electronic reference}

Célia Schneebeli, "Where /o/ Is: Function and Position of /o/ Used as a Discourse Marker in YouTube Comments", Discours [Online], 27 | 2020, Online since 23 December 2020, connection on 12 April 2021 URL: http://journals.openedition.org/discours/10900 ; DOI: https://doi.org/10.4000/discours.10900 

Revue de linguistique, psycholinguistique et informatique

\title{
Where Iol Is: Function and Position of Iol Used as a Discourse Marker in YouTube Comments
}

\author{
Célia Schneebeli \\ EA 4182 - Centre Interlangues \\ Université de Bourgogne
}





\title{
Where Iol Is: Function and Position of Iol Used as a Discourse Marker in YouTube Comments
}

\author{
Célia Schneebeli \\ EA 4182 - Centre Interlangues \\ Université de Bourgogne
}

\begin{abstract}
$\mathrm{Lol}$ is probably one of the most popular words in computer-mediated communication. It is generally taken to be the acronym of "laughing out loud", but it is not always used to indicate a humorous response; rather, it is multifunctional. Drawing on previous studies of the different functions of $10 /$, this paper explores a possible correlation between the position and function of non-lexicalized $/ 0 /$ in the specific context of YouTube comments. The hypothesis is that the function of lol largely depends on its position: clause-initial lol is not used with the same functions as clause-final lol. The data for the study come from the comment threads of three popular YouTube videos posted in 2017, 2018 and 2019 on the channel Miranda Sings, a channel posting humorous videos, which has a very wide audience and 10 million subscribers. The complete comment threads total 20,287 comments and 886 distinct occurrences of non-lexicalized lol. The analysis of the occurrences is both quantitative, aimed at determining the proportions of each use and position, and qualitative. Using the tools of discourse analysis and pragmatics, the study examines the functions of $/ 0 /$ on two levels: the level of discourse organization and the level of social interaction.
\end{abstract}

Keywords: Iol, YouTube, discourse marker, syntactic position, computer-mediated discourse pragmatic marker

Lol est probablement un des mots les plus caractéristiques du discours médié par ordinateur. "l est généralement présenté comme l'acronyme de "laughing out loud", qui signifie rire fort en anglais, mais il n'est pourtant pas toujours utilisé pour indiquer une réaction amusée et ses fonctions sont en réalité multiples. En s'appuyant sur les études précédentes qui se sont penchées sur le fonctionnement de lol, cet article explore la corrélation possible entre la position et la fonction des formes non lexicalisées de lol dans le contexte particulier des commentaires postés en réaction à des vidéos sur YouTube. II vérifie l'hypothèse selon laquelle la fonction de lol dépend largement de sa position: un lol utilisé en début de proposition n'a pas la même fonction qu'un lol utilisé en fin de proposition. Le corpus de l'étude est constitué des fils de commentaires de trois vidéos postées en 2017, 2018 et 2019 sur la chaîne YouTube humoristique Miranda Sings, qui compte 10 millions d'abonnés. Ces trois fils de commentaires représentent un total de 20287 commentaires, où on trouve 886 occurrences d'utilisations non lexicalisées de lol. L'analyse de ces occurrences est à la fois quantitative, elle cherche à déterminer la proportion de chaque fonction et position, et qualitative. À l'aide des outils de l'analyse du discours et de la pragmatique, l'étude examine les fonctions de lol à deux niveaux distincts: le niveau de l'organisation du discours et celui de l'interaction sociale.

Mots clés: Iol, YouTube, marqueur discursif, discours médié par ordinateur, position syntaxique, marqueur pragmatique 


\section{Introduction}

In a 2013 TED (Technology, Entertainment and Design) talk, McWhorter argued that lol "does not mean laughing out loud anymore" and has "evolved into something that is much subtler", such as "a marker of empathy", "a marker of accommodation" (McWhorter, 2013). While it is indeed true that the meaning of lol is quite subtle and variable, this overlooks the fact that online and offline, laughing, be it aloud or not, does not only mean expressing one's amusement. As many studies focusing on face-to-face interaction have shown, laughing has many other discursive and social functions. For instance, in a study dating back to 1983, O’Donnell-Trujillo and Adams isolated five functions of laughter in conversation: marking turn-taking, instructing a hearer on how an utterance is to be understood, evidencing how an utterance has been understood, inviting elaboration of problematic turns, and accomplishing affiliation. Therefore, laughter in face to face conversation is already multifunctional. As a result, its online counterpart, lol, may indeed have evolved, but its use was most probably never restricted to expressing one's amusement in the first place. Many scholars (for instance Baron, 2004; Tagliamonte \& Denis, 2008; Zappavigna, 2012; Markman, 2013; McSweeney, 2018) have already pointed out that $l o l$ is not always used to indicate a humorous response and have identified several other functions of lol. Yet, to the best of our knowledge, no study has investigated the possible link between lols function and its position in the message. This is precisely the twofold aim of the present study: it explores the functions of $l o l$ in a specific context (YouTube comments) and it examines the possible correlation between those functions and the position of lol. The hypothesis is that the function of $l o l$ largely depends on its position: clause-initial lol is not used with the same functions as clause-final lol or stand-alone lol.

While the starting point of the study is structural (place and position of lol in the utterance), the study itself focuses more on the interpersonal implications of lol use. Therefore, the approach used in this paper is a pragmatic approach, focusing on function and meaning in context and in the communicative situation.

\section{Data and methodology}

The data for the study come from the comment threads of three popular YouTube videos posted on the channel Miranda Sings. This channel has a very wide audience and 10 million subscribers and, what is even more important when studying lol, is specialized in humorous videos. The three videos in question are:

- "Destroying Toys with as Seen on TV Knifes" (posted on the 28th May 2017)

- "Why I'm in a Wheelchair Now" (posted on the 29th September 2018)

- "Baby Shark! *Emotional*" (posted on the 26th February 2019) 
The three complete comment threads were saved on the 3rd of March 2019. They total more than 20,000 comments $(20,287)$. Occurrences of lol and its typographic variants (with or without capitalization, with one or several "o" or " 1 ") were then extracted. Occurrences of lol used as a lexicalized word, in utterances such as verbal "I lol'd" or nominal "What a lol" or "For the lolz", were excluded since the study only concerns the original initialism. The final dataset comprises 886 distinct occurrences of non-lexicalized lol. The analysis of these occurrences is both quantitative, aimed at determining the proportions of each use and position, and qualitative. The study examines the functions of lol in the light of discourse analysis, on the level of discourse organization, but also on the pragmatic level of social interaction.

Lol has mostly been studied in multi-turn interactions online or in texting. YouTube comments, on the contrary, typically consist of single-turn dyadic interactions: the turn is initiated by the video, and the user's comment constitutes the reception of it, which completes the turn. As a result, even though they "display the intrinsic features of interaction" (Dynel, 2014: 38), YouTube comments cannot display phenomena pertaining to interactional coordination, which is essentially what other studies have focused on. The present study thus identifies the functions of $l o l$ in a different context, which complete the ones already identified in previous research.

\section{Syntactic position of $\mathrm{lol}$}

\subsection{Lol as a discourse marker}

The Oxford English Dictionary (OED) defines lol as an exclamation, that is "a short sound, word or phrase spoken suddenly to express an emotion”. In a similar way, lol is often described as an interjection, which Quirk et al.'s grammar defines as "purely emotive words that do not enter into syntactic relations" (Quirk et al., 1985: 853). Neither of the labels, which both focus merely on the expressive function of $l o l$, is accurate enough to describe how $l o l$ is used by speakers on the Internet. Instead of using these labels, Garley et al. (2009), Markman (2013), and Uygur-Distexhe (2014), showed that lol functions as a "discourse marker" in computer-mediated interaction. In her article focusing on $l o l, p t d r$ and $m d r$, Uygur-Distexhe offers the following definition of the term "discourse marker":

[E]xpressions that combine (i) "the semantics of discourse relational predications" (such as the attitudes of the speaker) with (ii) "syntactic dependency on a clausal host" and expressions with (iii) "low information salience".

(Uygur-Distexhe, 2014: 243)

What can be gathered from this definition is that, as a discourse marker, $l o l$ is an expression that has low informational content, gives information on the interpretation of the utterance (for example by signalling the attitude of the speaker), and depends on another unit of discourse, while not being integrated in the syntactic clause (which means it is extra-sentential). 
Because its meaning is more procedural than conceptual, it could also aptly be described as a "pragmatic marker". Aijmer and Simon-Vandenbergen make the following distinction between the two labels:

Discourse marker is the term which we use when we want to describe how a particular marker signals coherence relations. Pragmatic markers as we see them are not only associated with discourse and textual functions but are also signals in the communication situation guiding the addressee's interpretation.

(Aijmer \& Simon-Vandenbergen, 2006: 2)

However, since the present study also examines lols function in discourse organization, "discourse marker" has been preferred to "pragmatic marker". As a discourse marker, lol both marks discourse structure and relations, and gives instructions to the hearer concerning its interpretation.

\subsection{Lol placement in YouTube comments}

As Uygur-Distexhe rightfully notes, "discourse markers are not integrated into the syntactic clause, but this does not mean that they are outside the syntax" (UygurDistexhe, 2014: 244). This means that their placement or distribution is not free and that it is therefore always meaningful. Aijmer argues that "pragmatic markers do not occur anywhere in the utterance or the turn but there are rules for their placement which also have to do with their function" (Aijmer, 2013: 16). In the case of lol, its being extra-sentential means that its distribution is mostly limited to three possible positions in the utterance: clause-initial, clause-final or stand-alone. Clause-medial lol is highly unlikely and is in fact not present in the dataset. In her study of $l o l$ in text messages, McSweeney writes that "lol' almost always appears at the beginning or at the end of a message, and when it does appear in the middle of a message, it is between clauses" (McSweeney, 2018: 52). The same holds for the present dataset: there are cases of comment-medial lol, but in this case lol either appears at the end or at the beginning of the clause that it relates to. This seems quite logical for a discourse marker, which is never internal to the argument structure of the verb. In this perspective, the placement of lol seems comparable to that of laughter in conversation, which is unlikely to be found in the middle of sentences, as Provine argues:

Laughter occurs at places in the speech stream associated with pauses, phrase boundaries, and the beginning and ends of statements and questions. Thus, a speaker may say, "You are going where? ha-ha", but rarely "You are going -ha-ha- where?". (Provine et al., 2007: 300)

Of course, it may sometimes prove difficult to decide with certainty whether lol is clause-final or clause-initial when it is used in the middle of a comment. This is mostly the case in comments that contain no or unreliable punctuation, and/or no or unreliable capitalization. It may also be the case in comments whose meaning is unclear or which do not make sense at all. However, this is not very frequent, in part because multi-clausal comments are not numerous on YouTube comment threads, and it amounts to less than $1 \%$ of all occurrences in the dataset under study. 


\begin{tabular}{|l|r|}
\hline Position of lol & Occurrences \\
\hline clause-initial & $185 / 886(20.9 \%)$ \\
\hline clause-final & $485 / 886(54.7 \%)$ \\
\hline stand-alone & $209 / 886(23.6 \%)$ \\
\hline unclear & $7 / 886(0.8 \%)$ \\
\hline
\end{tabular}

Table 1 - Position of $l o l$ in the dataset

The first two positions are when $l o l$ is used alongside a clause in a comment. In this case, it is either clause-initial or clause-final.

\subsection{Clause-initial position}

Clause-initial $l o l$ is when lol is located at the front, or on the left, of a clause:

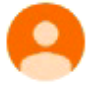

il y a 2 mois

Lol you can hear flynn in the back round singing

It I RÉPONDRE

In this case, it is clearly located outside the argument structure of the verb, sometimes by means of punctuation:

il y a 1 jour

Lol. My kids have been singing this song every day for the last month.

i RÉPONDRE

It should be noted that the presence or absence of punctuation may not be significant as punctuation is often used in a non-standard way in CMC (computermediated communication). It is therefore not always reliable. This is all the more true for final punctuation, which is very often omitted (for a study of non-standard punctuation in CMC, see Bieswanger, 2013: 476-478).

It should also be pointed out that clause-initial $l o l$ is not necessarily located at the beginning of the comment. As mentioned above, some occurrences of lol appear in the middle of a comment but are still to be considered clause-initial or final since they appear at the end or at the beginning of the clause that they relate to. Nevertheless, as the vast majority of YouTube comments are not multiclausal, there is little difference between clause-initial, sentence-initial and comment-initial position.

\subsection{Clause-final position}

Clause-final lol is used at the end, which means on the right, of a clause. Most of the time, it is not clearly separated from the argument structure of the verb, even though it is not integrated into it and does not belong to its argument structure: 


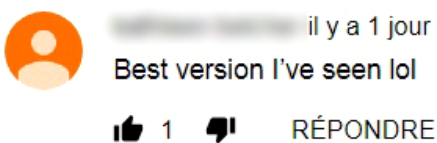

But punctuation is again sometimes used to separate it from the clause, with the same questionable reliability and significance which has been noted above:

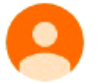

il y a 2 mois

Mommy shark duck doo doo doo doo. Lol

It RÉPONDRE

In this comment, $l o l$ is syntactically separated from the clause but it seems to make no significant difference in terms of meaning and function compared to the preceding comment, where it is not separated from the clause.

\subsection{Stand-alone $/ o l$}

The third and last position in which $l o l$ is used by commenters is a little different from the first two because this time, it implies that lol is used with no accompanying clause:

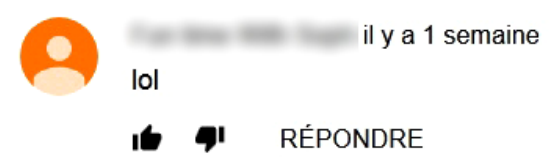

However, it can sometimes be used alongside modalities that have the same function, for example lol and an emoji "crying tears of joy", or $l o l$ and more traditional interjections such as $b a b a$ :

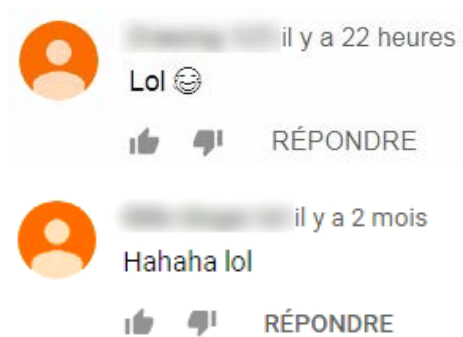

In all such cases, $l o l$ is used to duplicate the content of another modality; it is not used to accompany or modify clausal content and it has therefore been considered as belonging to the "stand-alone" category.

\section{Functions of lol in each position}

\subsection{A context-dependent marker}

In order to understand the function of lol, one has to look to both its immediate and its more general context. This is arguably the case for any discourse marker since a discourse marker is a "sequentially dependent element that brackets units 
of talk", which then functions "in relation to ongoing talk and text" (Schiffrin, 2005: 57). As a discourse marker, the meaning of $l o l$ is therefore highly relational and cannot be processed in isolation. This is why it is difficult to give a definition of $l o l$, and, for instance, why the $O E D$ defines it through its functions - expressive and pragmatic - and not by a stable semantic content. This is logical enough if we follow Fraser's description of discourse markers: they signal "a relationship between the interpretation of the segment they introduce, S2, and the prior segment, S1" and "have a core meaning which is procedural, not conceptual"; while "their more specific interpretation is 'negotiated' by the context, both linguistic and conceptual" (Fraser, 1999: 931). This is also the case of lol: its core meaning is procedural since it indicates an attitude. The attitude in question can be understood only through reference to the context, both narrow (the utterance lol may accompany) or more general (the interaction or situation). As a result, the precise value of lol in each utterance where it is used is context-dependent.

In the case of a comment posted on YouTube, the context in question can be a preceding utterance, some part of the utterance where lol appears, to its left or right, or the video which is being commented on.

\subsection{Functions of stand-alone $10 /$}

Stand-alone $l o l$ is rather frequent since it totals nearly a quarter of all occurrences of $l o l$ in the dataset. Its most obvious function generally corresponds to the straightforward expressive function of lol, which is showing one's amusement:

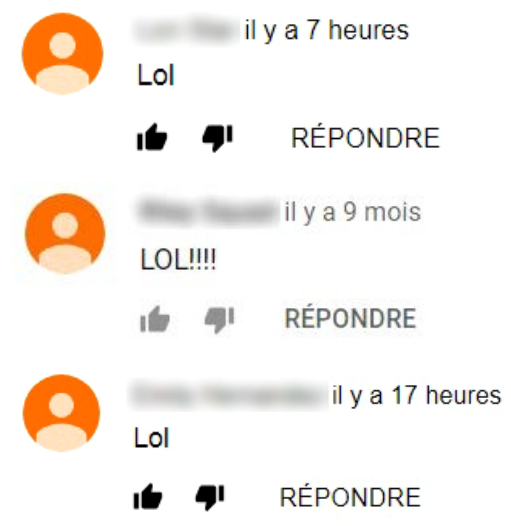

Stand-alone $l o l$ is particularly frequent among the first comments posted on all three videos. Commenters on YouTube often try to be the first to post a comment, or at least to be one of the "early" commenters. To do that they need to post the quickest reaction that comes to their mind, which, for a humorous video, is often a stand-alone lol.

All the comments above have approximately the same value and content as a complete clause saying "I found that funny". The primary function of $l o l$ is then to express the fact that the commenter found the video funny, albeit in a faster 
and more synthetic way. However, this is not its only function here. As Schiffrin notes, markers work at different levels of discourse and can act on different planes of talk at the same time (Schiffrin, 2005: 57). This is the case of lol: apart from its expressive function, stand-alone lol also achieves a second concomitant function, which is a socio-pragmatic function, located at the level of the interaction. The stance-taking theory of Du Bois (2007) may be of some help in understanding what this second function is about. For Du Bois, one of the most important stakes of interaction is for participants to position themselves and position others and objects of interest in and by language. This means that interpersonal issues such as appraisal and alignment are at the heart of interaction. This is all the more true in comments posted on social media, whose main purpose is to position oneself with respect to the object being commented on. Commenting on a video basically means taking a stance with respect to the video. By using lol to express their amusement, commenters also approve of the video or align with it or its author. Lol, in this perspective, can be considered as a stance-taking device. Its function is not only expressive but socio-pragmatic: it enables the commenter to "display a participation framework", in Schiffrin's words (Schiffrin, 2005: 57).

\subsection{Functions of clause-initial lol}

In the dataset, clause-initial lol is almost as frequent as stand-alone lol, and it has many similarities with it. First of all, it fulfils functions similar to stand-alone lol. Namely, it has an expressive function (expressing amusement), and in doing so it has a socio-pragmatic function (expressing approval and alignment). However, contrary to stand-alone lol, it can function in two different ways: it can refer back to the whole video and be followed by a clause which develops this initial reaction, or it can sometimes refer forward to a specific element in the video which is mentioned on the right.

\begin{tabular}{|l|l|}
\hline Function of clause-initial lol & Occurrences \\
\hline $\begin{array}{l}\text { expressing amusement and alignment/ } \\
\text { backward reference to the video }\end{array}$ & $160 / 185(86.5 \%)$ \\
\hline $\begin{array}{l}\text { expressing amusement and alignment/ } \\
\text { forward reference to a precise element of the video }\end{array}$ & $25 / 185(13.5 \%)$ \\
\hline
\end{tabular}

Table 2 - Functions of clause-initial lol in the dataset

The most frequent functioning is the first, where clause-initial lol refers to the whole video. Indeed, in most cases in the dataset, clause-initial lol is also comment-initial and in this case, it constitutes a first reaction to the video which is then developed or completed on the right, in the rest of the comment. This pattern is rather frequent in the dataset since it concerns $18 \%$ of all occurrences of lol. Here is one such comment: 
il y a 4 heures

LOL This is better than the original one!

i RÉPONDRE

Just like stand-alone lol, this occurrence of clause-initial lol expresses a first, immediate or spontaneous reaction that precedes verbal expression. The clause that follows, "this is better than the original one", then offers an additional comment that develops the initial reaction or completes it. This two-step operation is even clearer in comments which clearly separate comment-initial lol and the following clause by means of punctuation. In this case, comment-initial lol clearly functions as stand-alone lol:

il y a 11 mois

LOL!!!!!!!!! You're so mean!!! Hahahahaha!!!!!!!!!!

1) I RÉPONDRE

The clause that follows lol in this pattern of use may develop the initial reaction or not. Sometimes it does:

il y a 2 mois (modifié)

Lol so funny and emotional your the best Miranda

I. II RÉPONDRE

In the comment above, "so funny" confirms the user's reaction to the video. But sometimes the following clause has very little to do with the initial reaction:

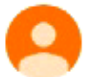

\section{il y a 1 an}

Lol I luv haters back off

It qI RÉPONDRE

The second part of this comment does not even concern the video since it is about Miranda's TV show, "Haters Back Off". What it does, however, is make the participation framework explicit. "I luv haters back off" displays positive appraisal of Miranda Sings, and so does "you're the best Miranda" in the preceding comment. Both comments contain direct expressions of alignment that confirm or make explicit what lol already implies.

In such comments, the meaning of lol is processed through backward reference. The reaction is expressed with respect to the whole video and the clause that follows lol only completes the reaction. Interestingly enough, a second pattern is present in the dataset, which this time implies forward reference. In this case, the element to which lol expresses a reaction is not the video as a whole but some specific part of it which is mentioned in the clause on the right, by means of a precise timing:

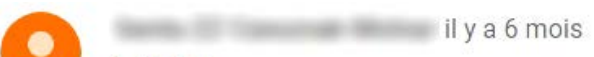

lol 1:20

It qI RÉPONDRE 
Or through a quotation:

Lol "if you ax me"

I RÉPONDRE

Or thanks to any mention of an element appearing in the video:

(2) ily a 1 an

Lol the barbie + choppie choppie rollie rollie

I) RÉPONDRE

This is particularly interesting since backward reference is generally said to be a more frequent, or a more natural way to process information in discourse, than forward reference. Indeed, as Beeching and Detges write, "a basic property of human language is that discourse unfolds in time", a property which is "represented in Western linguistics as progression from 'left' to 'right" (Beeching \& Detges, 2014: 1). Since discourse builds from left to right, co-referent elements point backwards, to what has already been said or mentioned, more often than forwards.

In the dataset too, forward reference to an element mentioned on the right is far less frequent than backward reference since it concerns only 25 occurrences. The reverse pattern implying backward reference, which is a comment composed of a quotation, a timing or the mention of a precise element of the video followed by lol, is much more frequent since it concerns 162 occurrences. This may be due to the fact that the passage mentioned or quoted is the topic of the message. Thus, it is what needs to be mentioned first for the message to be more easily understood. For the same reason, it also seems more logical to provide the object of the reaction before the reaction itself.

\subsection{Functions of clause-final /ol}

Clause-final $l o l$ is the most frequent position in the dataset, and by far, since it concerns more than half of all occurrences. It is also the richest in terms of functions since, similarly to clause-initial and stand-alone lol, it has an expressive function (expressing amusement) and a concomitant socio-pragmatic function (expressing alignment), but it also has two other functions:

\begin{tabular}{|l|r|}
\hline Function of clause-final lol & Occurrences \\
\hline expressing amusement and alignment & $162(33.4 \%)$ \\
\hline illocutionary marker & $252(52 \%)$ \\
\hline phatic function & $64(13.2 \%)$ \\
\hline unclear & $7(1.4 \%)$ \\
\hline
\end{tabular}

Table 3 - Functions of clause-final lol 
Again, clause-final lol can be used to react to a precise element of the video and align oneself with the video or Miranda. In this case, as explained above, the element, passage, or quotation which the user reacts to is mentioned first and $l o l$ is inserted on the right (and can be further developed by a following clause):

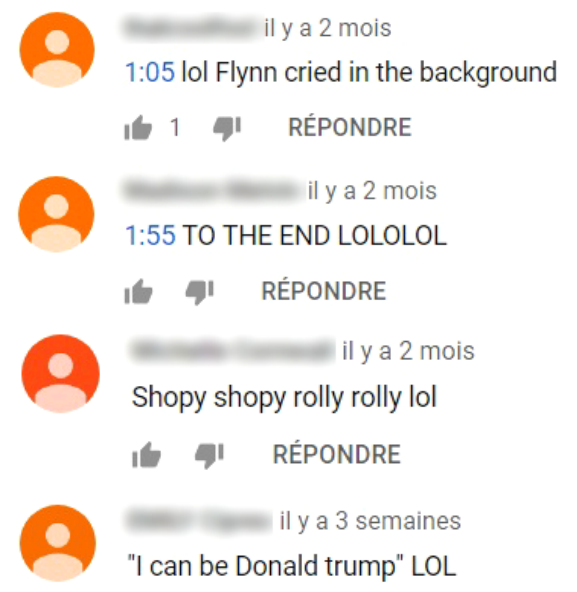

This is frequently the case since about $33 \%$ of clause-final lols have this function $(162 / 485)$. However, clause-final lol also offers two other functions which do not seem to be accessible to sentence-initial lol or stand-alone lol, one of which is in fact the most frequent function of clause-final lol.

The first one more or less corresponds to O'Donnell-Trujillo and Adams' conception of "laughter as instruction to hear" (O'Donnell-Trujillo \& Adams, 1983: 186), or the role of laughter in giving information on how an utterance is to be taken in face-to-face conversation. This function has already been analyzed by CMC scholars with respect to emoticons and emoji. For instance, Walther and D'Addario (2001) explored how emoticons contribute to message interpretation. Dresner and Herring (2010) then developed the idea that emoticons may be used as illocutionary force markers. In a similar way, lol can indicate that a remark is not to be taken literally, or that it is meant as a joke. This function is in fact the most frequent function of clause-final $l o l$, and the most frequent function of $l o l$ in the whole dataset: $28 \%(252 / 886)$ of all occurrences of lol are used at the end of clauses that would have a different force without it, or that would be interpreted differently. In this case, lol can be identified as an illocutionary force marker in a way similar to emoticons and emoji. It is used to clarify "the illocutionary force of [the] message, primarily through modulating either the strength of the illocutionary point or the speaker's commitment to the illocutionary point" (McSweeney, 2018: 56). In the following comment, for instance, it enables a commenter to indicate that her comment is not to be taken at face value:

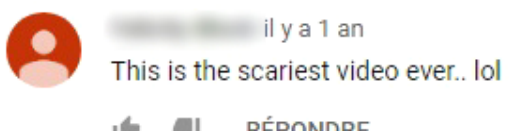


Lol indicates that the video is not really the scariest video ever and that the remark is to be taken as a joke. In this respect, lol also functions to soften or mitigate a potentially aggressive utterance and, as a result, to manage facework (i.e., not hurting the hearer's feelings, defusing potential tension) online:

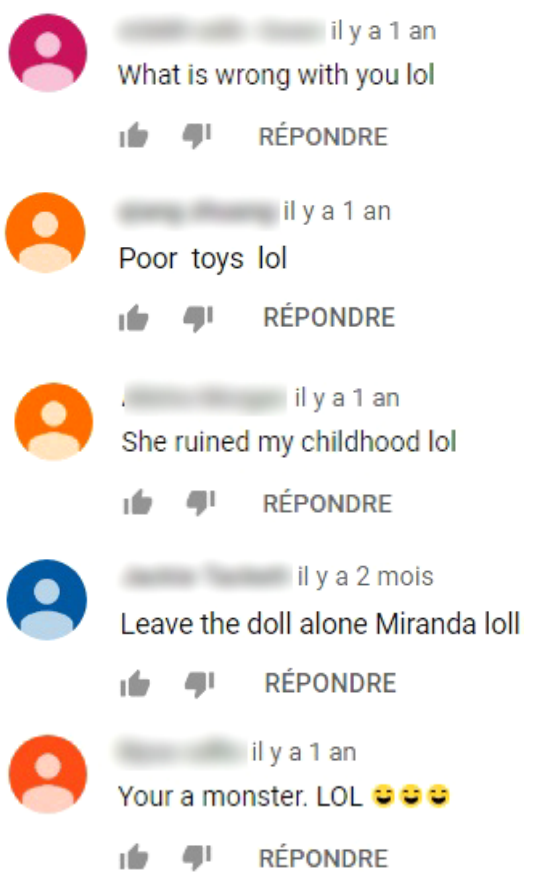

All these comments contain remarks that could be perceived as accusatory ("what is wrong with you", "you are a monster"), aggressive (the command "leave the doll alone"), or more generally negative (the complaint "poor toys"). But in all of them, lol calibrates the force of the utterance and provides a clue as to how it is to be perceived (namely as a joke/not at face value). If lol was removed, the comment could be taken as a piece of criticism or aggression. Adding lol, which is then used as a softener, therefore also serves to defuse potential tension or aggressiveness.

The second function exclusive to clause-final $l o l$ is when $l o l$ is inserted after a statement that seems neither humorous nor ambiguous or aggressive, and whose meaning therefore appears to be literal. In such a context, lol does not seem to be needed and could well be deleted without changing the force and meaning of the clause:

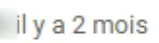

Hy Miranda!! $\rightarrow$ lol great new song I love u and missed you lol

It II RÉPONDRE

il y a 2 mois

I was crying and laughing at the same time! Poor Flynn! I love you Miranda! Lol

It 1 II RÉPONDRE 


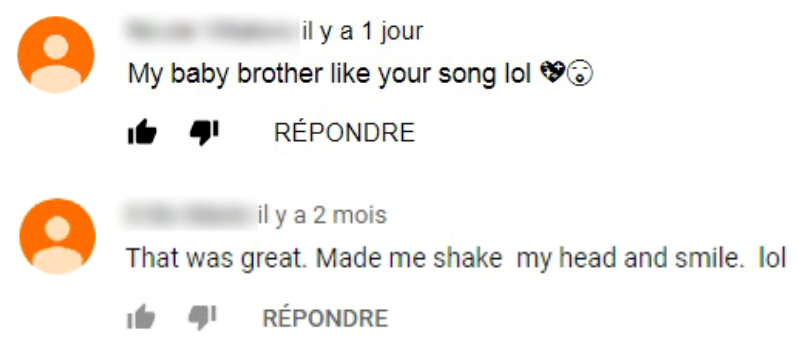

Using lol alongside an utterance whose meaning is literal, or that does not require mitigation, is relatively frequent since it is the case in 64 occurrences of lol in the dataset. Why, then, is lol used at the end of these clauses? Provine provides one possible explanation in a 1996 article which reports on a study on laughter in face-to-face conversation where he and his team found that most of the time, laughter seems to follow banal remarks. He suggests that laughter, in this case, has a social or phatic function: it is aimed at creating empathy. Similarly, in the comments above, lol is not used to express amusement or manage illocutionary force; rather, it functions as a way to bond with the potential reader by showing the commenter's benevolent state of mind. This is especially obvious in comments that are addressed to other readers, such as the comment at the bottom of the page:

il y a 1 an

anyone else think of sid from toy story when whe was putting the toys together lol??

I)

This comment is not particularly humorous, or offensive, or meant as a joke, and it has no double meaning either. In this case, lol seems to merely aim at creating complicity, in the fashion reported by Provine. This may be rather ironic in a world of single-turn interactions such as YouTube comment threads, where most comments are never responded to.

It is to be noted that contrary to other discourse markers such as "well", whose canonical meaning is "good" but has taken on an altogether different procedural meaning in conversation (see Beeching \& Wang, 2014, for a study of this semantic shift), lol's canonical meaning, expressing laughter in CMC, already served those pragmatic functions in face-to-face interaction. It is therefore difficult to talk of the "pragmaticalisation" of $l o l$ when $l o l$ is used as an illocutionary force marker or with a phatic function.

\section{Conclusion}

The conclusion to this study is threefold.

A first conclusion is that lol enables internet users to still laugh online. It may not always literally be a loud laugh, it may just be a chuckle, a chortle or a snort, but it is still a laugh, which has most of the functions of laughter in face-to-face interaction. 
A second conclusion is that lol has functions that are comparable to emoji and emoticons and other more traditional interjections such as $b a b a$. Further research would be needed to try and see whether there is any specialized use and factors of choice emerging between these markers.

The last conclusion is the answer to this paper's opening research question, which is the possible correlation between the position and function of lol. The initial hypothesis proved to be partly wrong. Indeed, lol can be used to express a reaction and hence, as an indicator of stance, can be used in any position: alone, in front of, or at the end of a clause. Nevertheless, position is not unrelated to function since some functions seem to be reserved to final position. In this position, lol often functions as a kind of punctuation, in the same way as emoticons and emoji that appear at the end of an utterance, whose use is comparable to question marks or exclamation marks according to Dresner and Herring (2010: 263). In this regard, lol verifies part of the initial postulate of Beeching and Detges (2014) that left-peripheral elements tend to have a discourse-structuring function and that right-peripheral elements tend to have an intersubjective or modalising role. While left-peripheral lols do not always function as discourse-structuring elements, right-peripheral lols share the same modal function and, like the right-peripheral elements studied by Beeching and Detges, they "seem to reflect or invite attitudes towards the message or the situation rather than contributing to the message itself" (Beeching \& Detges, 2014: 4).

\section{References}

Aijmer, K. 2013. Understanding Pragmatic Markers in English. A Variational Pragmatic Approach. Edinburgh: Edinburgh University Press.

Aijmer, K. \& Simon-Vandenbergen, A.-M. (eds.) 2006. Pragmatic Markers in Contrast. Studies in Pragmatics 2. Amsterdam - Oxford - Paris: Elsevier.

Baron, N.S. 2004. See You Online: Gender Issues in College Student Use of Instant Messaging. Journal of Language and Social Psychology 23 (4): 397-423.

Beeching, K. \& Detges, U. (eds.) 2014. Discourse Functions at the Left and Right Periphery: Crosslinguistic Investigations of Language Use and Language Change. Leiden - Boston: Brill.

BeEching, K. \& WAng, Y.-F. 2014. Motivations for Meaning Shift at the Left and Right Periphery: "well", "bon" and "hao". In K. Beeching \& U. Detges (eds.), Discourse Functions at the Left and Right Periphery: Crosslinguistic Investigations of Language Use and Language Change. Leiden - Boston: Brill: 47-71.

Bieswanger, M. 2013. Micro-Linguistic Structural Features of Computer-Mediated Communication. In S.C. Herring, D. Stein \& T. Virtanen (eds.), Pragmatics of Computer-Mediated Communication. Berlin: De Gruyter: 463-486.

Dresner, E. \& Herring, S.C. 2010. Functions of the Non-Verbal in CMC: Emoticons and Illocutionary Force. Communication Theory 20: 249-268.

Du Bors, J.W. 2007. The Stance Triangle. In R. EnGlebretson (ed.), Stancetaking in Discourse: Subjectivity, Evaluation, Interaction. Amsterdam - Philadelphia: J. Benjamins: 139-182. 
DyNEL, M. 2014. Participation Framework Underlying YouTube Interaction. Journal of Pragmatics 73: 37-52.

Fraser, B. 1999. What Are Discourse Markers? Journal of Pragmatics 31 (7): 931-952.

Garley, M., Slade, B. \& Terkourafi, M. 2009. Hwæt! LOl! Common Formulaic Functions in "Beowulf" and Blogs. Proceedings from the Annual Meeting of the Chicago Linguistic Society 45 (1): 111-126.

Markman, K.M. 2013. Exploring the Pragmatic Functions of the Acronym LOL in Instant Messenger Conversations. In International Communication Association Annual Conference, June 2013, London. 1-9. Available online: https://osf.io/preprints/socarxiv/3du86/ download.

McSweeney, M. 2018. The Pragmatics of Text Messaging: Making Meaning in Messages. New York: Routledge.

McWhorter, J. 2013. Txtng is Killing Language. JK!!! Video available online: https:// www.ted.com/talks/john_mcwhorter_txtng_is_killing_language_jk/transcript.

O’Donnell-Trujillo, N. \& Adams, K. 1983. "Heheh" in Conversation: Some Coordinating Accomplishments of Laughter. Western Journal of Speech Communication 47 (2): 175-191.

Provine, R.R. 1996. Laughter. American Scientist 84 (1): 38-45.

Provine, R.R., Spencer, R.J. \& Mandell, D.L. 2007. Emotional Expression Online: Emoticons Punctuate Website Text Messages. Journal of Language and Social Psychology 26 (3): 299-307.

Quirk, R., Greenbaum, S., Leech, G. \& Svartvik, J. 1985. A Comprehensive Grammar of the English Language. London - New York: Longman.

SCHIFFrin, D. 2005. Discourse Markers: Language, Meaning and Context. In D. Schiffrin, D. Tannen \& H.E. Hamilton (eds.), The Handbook of Discourse Analysis. Malden Oxford - Carlton: Blackwell Publishers: 54-70.

Tagliamonte, S.A. \& Denis, D. 2008. Linguistic Ruin? LOL! Instant Messaging and Teen Language. American Speech 83 (1): 3-34.

Uygur-Distexhe, D. 2014. "Lol”, “mdr" and "ptdr": An Inclusive and Gradual Approach to Discourse Markers. In L.-A. Cougnon \& C. FAIron (eds.), SMS Communication: A Linguistic Approach. Amsterdam - Philadelphia: J. Benjamins: 239-263.

WALther, J.B. \& D’ADDARIO, K.P. 2001. The Impacts of Emoticons on Message Interpretation in Computer-Mediated Communication. Social Science Computer Review 19 (3): 324-347.

Zappavigna, M. 2012. Discourse of Twitter and Social Media: How We Use Language to Create Affiliation on the Web. London - New York - New Delhi: Bloomsbury. 